\title{
Defective CFTR-regulated granulosa cell proliferation in polycystic ovarian syndrome
}

\author{
Hui Chen, Jing Hui Guo, Xiao Hu Zhang and Hsiao Chang Chan \\ Faculty of Medicine, School of Biomedical Sciences, Epithelial Cell Biology Research Center, CUHK-SJTU Joint \\ Center for Human Reproduction and Related Diseases, The Chinese University of Hong Kong, Sha Tin, \\ New Territories, Hong Kong
}

Correspondence should be addressed to H C Chan; Email: hsiaocchan@cuhk.edu.hk

H C Chan is now at The Chinese University of Hong Kong, Room 420A Lo Kwee-Seong Integrated Biomedical Sciences Building, Sha Tin, New Territories, Hong Kong

\begin{abstract}
Polycystic ovarian syndrome (PCOS) is one of the most frequent causes of female infertility, featured by abnormal hormone profile, chronic oligo/anovulation, and presence of multiple cystic follicles in the ovary. However, the mechanism underlying the abnormal folliculogenesis remains obscure. We have previously demonstrated that CFTR, a cAMP-dependent $\mathrm{Cl}^{-}$and $\mathrm{HCO}_{3}^{-} \mathrm{Conducting}$ anion channel, is expressed in the granulosa cells and its expression is downregulated in PCOS rat models and human patients. In this study, we aimed to investigate the possible involvement of downregulation of CFTR in the impaired follicle development in PCOS using two rat PCOS models and primary culture of granulosa cells. Our results indicated that the downregulation of CFTR in the cystic follicles was accompanied by reduced expression of proliferating cell nuclear antigen (PCNA), in rat PCOS models. In addition, knockdown or inhibition of CFTR in granulosa cell culture resulted in reduced cell viability and downregulation of PCNA. We further demonstrated that CFTR regulated both basal and FSH-stimulated granulosa cell proliferation through the $\mathrm{HCO}_{3}^{-}$/sAC/PKA pathway leading to ERK phosphorylation and its downstream target cyclin $\mathrm{D}_{2}$ (Ccnd2) upregulation. Reduced ERK phosphorylation and CCND2 were found in ovaries of rat PCOS model compared with the control. This study suggests that CFTR is required for normal follicle development and that its downregulation in PCOS may inhibit granulosa cell proliferation, resulting in abnormal follicle development in PCOS. Reproduction (2015) 149 393-401
\end{abstract}

\section{Introduction}

During an ovarian cycle, a set of resting follicles are recruited and enter growth phase upon the stimulation by a number of endocrine and paracrine factors (Edson et al. 2009, Oktem \& Urman 2010). The recruited follicles will undergo a selection process, during which one (in humans) or some (in rodents) of the recruited follicles with the growth/survival factors overwhelm the apoptotic factor, therefore continue(s) to develop and become(s) the dominant follicle(s), while the others are suppressed and finally committed to atresia (Edson et al. 2009, Oktem \& Urman 2010). Normal follicle development depends on the balance between proliferation and apoptosis process. Abnormal and dysregulated follicle growth is often observed in ovarian disorders and underlies female infertility.

Polycystic ovarian syndrome (PCOS) is known to be an endocrine disorder and the leading cause of female infertility (Teede \& Norman 2006, Norman et al. 2007). Apart from anovulation/oligoovulation and abnormal androgen-to-estrogen ratio in serum, another characteristic and diagnostic criterion of PCOS is the presence of multiple cystic follicles in the ovary. The cystic follicles are observed as 'arrested', as none of them can grow further to become a dominant follicle committed to ovulation as observed in a normal cycle. These follicles show signs of atresia and degeneration of the granulosa cell layers (Broekmans \& Fauser 2006), suggesting abnormal proliferation and/or apoptosis in granulosa cells of these follicles, resulting in failure in further development. However, the cause of abnormal follicle development in PCOS is unclear.

While preantral follicle development depends on local growth factors, antral follicle growth critically depends on follicle-stimulating hormone ( $\mathrm{FSH}$ ) derived from the pituitary (Kumar et al. 1997, Edson et al. 2009, Oktem \& Urman 2010). FSH induces granulosa cell proliferation by regulating cell cycle activator cyclin $\mathrm{D}_{2}$ (CCND2) and cell cycle inhibitor p27 $7^{\text {kip }}$ (Robker \& Richards 1998a, Hunzicker-Dunn \& Maizels 2006, Muniz et al. 2006) through the PI3K/Akt (Park et al. 2005, Han et al. 2013) or MAPK/ERK pathway (Kayampilly \& Menon 2004). Although FSH levels in PCOS patients are usually in the normal range (Broekmans \& Fauser 2006), the aberrant 
antral follicle development observed in PCOS suggests that there may be defect in FSH signaling in PCOS, resulting in reduced proliferation of granulosa cells.

Women with cystic fibrosis (CF), the most common genetic disease in Caucasians caused by mutations of CFTR (Kerem et al. 1989, Riordan et al. 1989, Rommens et al. 1989), also exhibit delayed puberty, anovulation, oligoovulation, amenorrhea (Stead et al. 1987, Aswani et al. 2003), cystic ovaries, and abnormal hormone levels similar to that observed in PCOS women (Shawker et al. 1983). Although CFTR has been demonstrated to be expressed in the female reproductive tract, including the ovary (Trezise et al. 1993, Chan et al. 2002), and involved in uterine $\mathrm{HCO}_{3}^{-}$secretion (Wang et al. 2003) and $\mathrm{HCO}_{3}^{-}$ transport that is required for sperm capacitation (Xu et al. 2007, Chen et al. 2012a), the role of CFTR in ovarian function remained unknown for a long time. Recently, we have demonstrated that CFTR is expressed in human and rodent granulosa cells and involved in the regulation of the FSH-stimulated aromatase expression and estrogen production through an $\mathrm{HCO}_{3}^{-} / \mathrm{sAC}$-dependent pathway (Chen et al. 2012b). In addition to abnormal hormone levels, polycystic ovaries associated with PCOS have also been observed in some CF women, suggesting a possible role of CFTR in the development of polycystic ovaries in addition to abnormal estrogen production in PCOS (Chen et al. 2012b). As FSH signaling plays an important role in regulating granulosa cell proliferation/apoptosis (Robker \& Richards 1998b, Hussein 2005, Edson et al. 2009, Oktem \& Urman 2010) and CFTR is able to modulate the FSH signaling in granulosa cells (Chen et al. 2012b), we suspected that CFTR might also influence the FSH signaling in regulating the proliferation and apoptosis of granulosa cells. We undertook this study to test this hypothesis. The results indicate that CFTR-dependent signaling potentiates the FSH/MAPK/ERK signaling and that granulosa cell proliferation can be affected by CFTR expression/function. These findings provide a novel molecular mechanism that may contribute to the abnormal follicle growth observed in PCOS.

\section{Materials and methods}

\section{Animals}

Female Sprague-Dawley (SD) rats and female Institute for Cancer Research (ICR) mice were kept in the Laboratory Animal Service Center, the Chinese University of Hong Kong with $12 \mathrm{~h}$ light: $12 \mathrm{~h}$ darkness cycle and provided food and water ad libitum. Animals were killed by $\mathrm{CO}_{2}$ inhalation. All procedures were approved by the Animal Ethical Committee of the Chinese University of Hong Kong.

\section{PCOS models}

Rat PCOS models were established as described previously (Chen et al. 2012b). For testosterone-induced PCOS model, 9-day-old SD rats were injected s.c. with $1.25 \mathrm{mg}$ testosterone dissolved in corn oil. For vehicle control, only coin oil was injected. Rats were killed at the age of 70 days. Ovaries were collected for further analyses. For human CG (hCG) plus L-norgestrel-induced PCOS model, a piece of $3 \mathrm{~mm}$ L-norgestrel silica gel was embedded s.c. in the SD rat at the age of 24 days. From the age of 27 days, rats were injected with $1.5 \cup$ hCG twice a day for a period of 9 days. For the control group, rats received sham operation and saline injection. Rats were killed at the age of 36 days. Ovaries were collected for further analyses.

\section{Granulosa cell culture}

Ovaries were collected from 25-day-old female ICR mice. Ovaries were washed once in Hank's balance salt solution, and transferred to DMEM/F12 containing $10 \%$ fetal bovine serum, $100 \mathrm{U} / \mathrm{ml}$ penicillin, and $100 \mathrm{mg} / \mathrm{ml}$ streptomycin. Large preantral follicles were punctured by 25 -gauge needles. Granulosa cells were released into the medium by pressing the punctured follicles, and then collected by centrifugation at $500 \mathrm{~g}$ for $5 \mathrm{~min}$. Cells were seeded into six-well culture plates at a density of $1 \times 10^{6} /$ well. For ERK phosphorylation assay, on day 4 of culture, granulosa cells were pretreated with $\mathrm{HCO}_{3}^{-}$free DMEM/F12 medium without serum for $2 \mathrm{~h}$, followed by treatment of $\mathrm{HCO}_{3}^{-}$free medium with vehicle, or $25 \mathrm{mM} \mathrm{HCO}_{3}^{-}$medium with vehicle, $10 \mu \mathrm{M}$ CFTR inhibitor GlyH101, $10 \mu \mathrm{M}$ sAC inhibitor $\mathrm{KH}$ 7, or $20 \mu \mathrm{M}$ PKA inhibitor $\mathrm{H} 89$ in the presence or absence of $50 \mathrm{ng} / \mathrm{ml}$ FSH for 15 min.

\section{CFTR knockdown by siRNA}

Granulosa cells were transfected on day 3 of the primary culture. Cells were transfected with $40 \mathrm{nM}$ Stealth siRNA (siRNA1: 5'-UUGGAAAGAAGACUAACAAGUUGUC-3'; SiRNA2: 5'-AUUGAGAGCAGAAUGAAACUCUUCC-3') or the scrambled siRNA (low GC content) (Invitrogen, Cat. 12935-200) using lipofectamine 2000 (Invitrogen). At $48 \mathrm{~h}$ after transfection, whole-cell protein was extracted for western blot analysis.

\section{Immunofluorescence}

Ovaries from control or PCOS rats were fixed with 4\% paraformaldehyde overnight, dehydrated, and embedded by paraffin. The tissues were cut into $5 \mu \mathrm{m}$ paraffin sections. Before staining, the sections were rehydrated, followed by antigen retrieval in $10 \mathrm{mM}$ citric acid buffer $(\mathrm{pH}$ 6.0). For immunofluorescence, the sections were blocked with $1 \%$ BSA for $1 \mathrm{~h}$ and incubated with a rabbit anti-CFTR antibody (Alomone, Jerusalem, Israel, ACL-006, 1:50 dilution) at $4{ }^{\circ} \mathrm{C}$ overnight. The sections were washed three times with PBST. Then, the sections were incubated with Alexa Fluor 488-conjugated secondary antibodies (Invitrogen) for $1 \mathrm{~h}$ at room temperature. The slides were mounted with Prolong $(R)$ Gold Antifade Reagent (Invitrogen, Cat. P36934). Images were obtained at the same setting under the Carl Zeiss LSM5 PASCAL Confocal microscope. 


\section{Quantitative RT-PCR}

Total RNA was extracted with TRIzol reagent (Invitrogen). Two micrograms of RNA were reverse transcribed into cDNA using MMLV reverse transcriptase. One microliter of cDNA was mixed with forward and reverse primers (Ccnd2: forward, 5'-ATGCTGCTCTTGACGGAACT-3' and reverse, 5' -CСТCACGACTTCATTGAGCA-3'; Gapdh: forward, 5'-GACCACAGTCCATGACATCACTGC-3' and reverse, 5'-GCTGTTGAAGTCGCAGGAGACAAC-3') and $2 \times$ iTaq SYBR Green Universal Supermix (Bio-Rad, 172-5121). PCR was performed on Applied Biosystem 7500 fast real-time PCR system. The program was run at $95{ }^{\circ} \mathrm{C}$ for $10 \mathrm{~min}, 40$ cycles of $95^{\circ} \mathrm{C}$ for $15 \mathrm{~s}, 60{ }^{\circ} \mathrm{C}$ for $60 \mathrm{~s}$, followed by elevation to $95^{\circ} \mathrm{C}$ by $1{ }^{\circ} \mathrm{C} / \mathrm{min}$, holding at $95^{\circ} \mathrm{C}$ for $30 \mathrm{~s}$, and $60{ }^{\circ} \mathrm{C}$ for $15 \mathrm{~s}$. A final melting curve showed a single peak of each PCR. PCR products were sequenced and blasted to confirm the specificity of the primers. The relative expression level was calculated by the $\Delta \Delta C$ t method.

\section{Western blot}

Protein lysate was prepared from ovaries of PCOS model and cultured granulosa cells with RIPA buffer containing $10 \mathrm{mMTris-Cl}$ $\mathrm{pH}$ 8.0, $150 \mathrm{mM} \mathrm{NaCl}, 2 \mathrm{mM}$ EDTA, $50 \mathrm{mM} \mathrm{NaF}, 0.1 \%$ SDS, $1 \%$ NP-40, 1\% sodium deoxycholate, $1 \mathrm{mM}$ phenylmethylsulphonyl fluoride, and protease inhibitor cocktail (Roche, 11697498001). Protein was denatured by Laemmli sample buffer and heated to $95{ }^{\circ} \mathrm{C}$ for $5 \mathrm{~min}$. Proteins were separated by SDS-PAGE and blotted onto nitrocellulose membrane. Blots were blocked with $5 \%$ nonfat dry milk in TBS-T for $1 \mathrm{~h}$ at room temperature and incubated with primary antibodies at $4{ }^{\circ} \mathrm{C}$ overnight. Rabbit anti-CFTR antibody (Alomone, ACL-006) was diluted at 1:200; mouse antiproliferating cell nuclear antigen (PCNA) (Santa Cruz, sc-56), rabbit anti-ERK (Cell Signaling, 9102; Danvers, MA, USA), rabbit anti-phospho-ERK (Cell Signaling, 9101), and rabbit anti-cleaved caspase 3 (Cell Signaling, 9661) antibodies were diluted at 1:1000; rabbit anti-Ccnd2 antibody (Santa Cruz, sc-181) was diluted at 1:200. After three washes with TBS-T, blots were incubated with HRP-conjugated anti-mouse or anti-rabbit IgG. Signals were detected with $\mathrm{ECL}$ western blotting detection reagent (GE Healthcare, Pittsburg, PA, USA). Band intensity was measured by Alphalmager System (ProteinSimple, San Jose, CA, USA) and quantified by the average density value of the selected area with the same size. Relative protein expression was quantified by the ratio of target protein band intensity to $\beta$-tubulin band intensity. Ratio of phospho-ERK band intensity to total ERK band intensity was used for quantification of ERK phosphorylation.

\section{Cell viability assay}

Granulosa cells were seeded into a 96-well plates at a density of $2 \times 10^{5}$. On the 2 nd day of the culture, cells were treated with $0.1 \%$ DMSO (v/v) or $10 \mu \mathrm{M}$ GlyH101 in DMEM/F12 containing $10 \%$ FBS. For FSH treatment, cells were treated with $0.1 \%$ DMSO, $0.1 \%$ DMSO plus $50 \mathrm{ng} / \mathrm{ml} \mathrm{FSH}$ or $10 \mu \mathrm{MGlyH} 101$ plus $50 \mathrm{ng} / \mathrm{ml}$ FSH in serum-free medium. For siRNA transfection, cells were seeded into 96-well plates. At $24 \mathrm{~h}$ after seeding, cells were transfected with $40 \mathrm{nM}$ Stealth siRNA or scramble control as described in CFTR knockdown by siRNA section In MTS assay,
$20 \mu \mathrm{l}$ MTS (3-(4,5-dimethylthiazol-2-yl)-5-(3-carboxymethoxyphenyl)-2-(4-sulfophenyl)-2H-tetrazolium) solution (Promega) was diluted in $100 \mu \mathrm{l}$ medium in each well. After $2 \mathrm{~h}$ of incubation at $37^{\circ} \mathrm{C}$, absorbance was read at a wavelength of A490 nm.

\section{Statistical analysis}

Statistics analysis was performed with three to four animals per group or three to four independent cultures. Data are expressed as mean \pm s.E.M. Two-tail unpaired Student's $t$-tests were used for two groups of comparison. One-way ANOVA and Tukey's post hoc test were used for comparison among three or more groups. $P<0.05$ was considered statistically significant.

\section{Results}

\section{Reduced CFTR expression in granulosa cells of tertiary/cystic follicles in PCOS rat models}

Our previous study had revealed that CFTR was downregulated in the ovaries of PCOS rats (Chen et al. 2012b). In this study, we further investigated CFTR expression profile in different types of follicles. As shown in Fig. 1, immunofluorescence showed that in L-norgestrel + hCGinduced PCOS rats, the granulosa cells of the tertiary and cystic follicles exhibited lower CFTR expression compared with the healthy tertiary follicles of the control rats, whereas the signal difference in secondary and early tertiary follicles between PCOS and control rats was less prominent (Fig. 1A). In testosterone-induced PCOS rats, CFTR-positive signal is also reduced in granulosa cells of the cystic follicles compared with that in the healthy tertiary follicles of the control rats, whereas the signals in both control and PCOS secondary follicles were similar (Fig. 1B). These results suggest that CFTR in granulosa cells may be important for tertiary follicle development and that its downregulation may contribute to the formation of cystic follicles in PCOS.

\section{Downregulation of PCNA in PCOS ovaries}

We further examined whether apoptosis and/or proliferation was altered in PCOS ovaries. Western blot results indicated that there was no significant change in cleaved caspase 3, which is the central executor of apoptosis, between the control groups and PCOS groups in L-norgestrel + hCG- or testosterone-treated model (Fig. 2A and B). However, PCNA, a protein required for DNA synthesis and cell proliferation, was significantly downregulated in the ovaries of both PCOS models, indicating reduced cell proliferation in the PCOS ovaries (Fig. 2A and B).

\section{CFTR affects viability of granulosa cells}

In order to investigate the role of CFTR in granulosa cell proliferation, we examined the effect of CFTR inhibitors on the viability of granulosa cells. MTS cell viability 

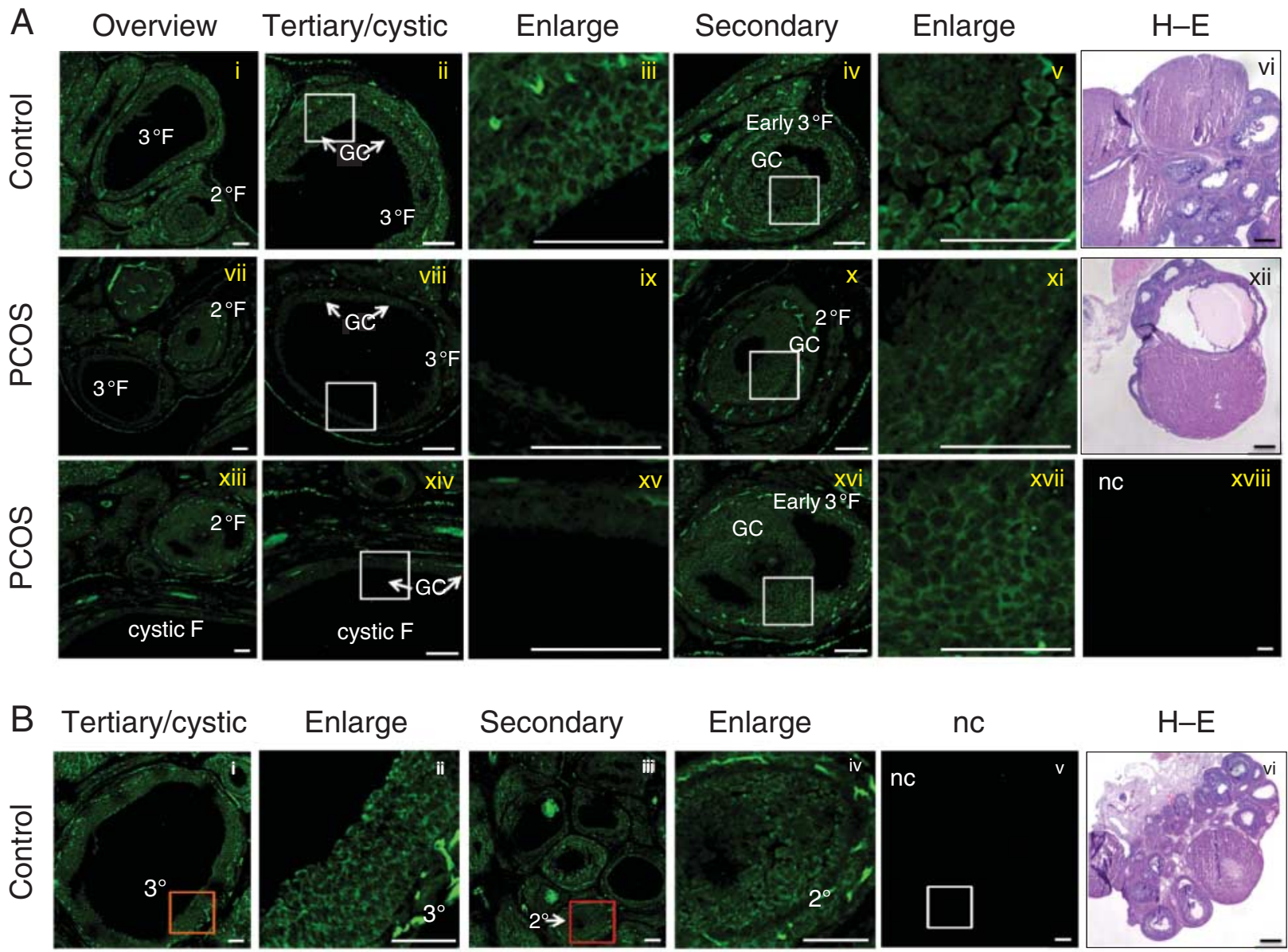

Secondary

\section{Enlarge}
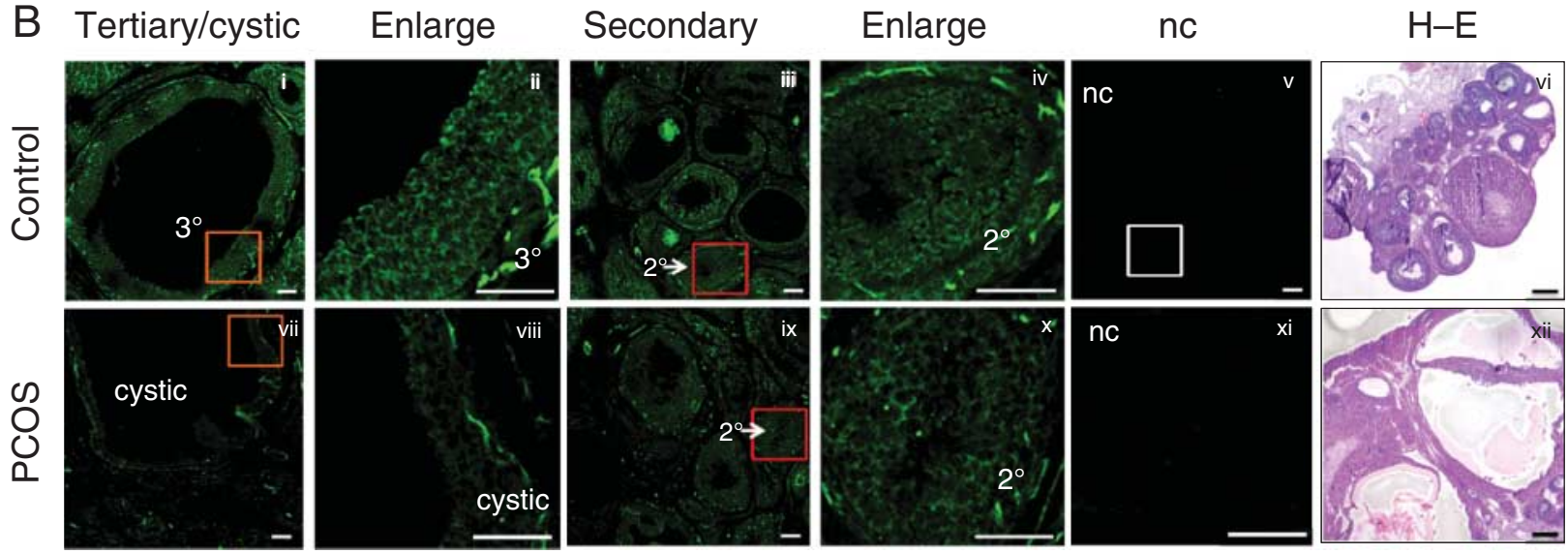

Figure 1 Immunofluorescence of CFTR and H-E staining in the ovaries of rat PCOS models. (A) Immunofluorescence of CFTR and H-E staining in the ovaries of control (i, ii, iii, iv, v, and vi) and L-norgestrel + hCG-induced PCOS model (vii, viii, ix, x, xi, xii, xiii, xiv, xv, xvi, xvii, and xviii). CFTR signal is reduced in granulosa cells of tertiary $\left(3^{\circ} \mathrm{F}\right.$ ) (viii and ix) and cystic follicles (cystic F) (xiv and $\mathrm{xv}$ ) of PCOS rats compared with that in the healthy tertiary follicles of control rats (ii and iii). CFTR signal in the granulosa cells of the secondary $\left(2^{\circ} \mathrm{F}\right.$ ) and early tertiary (early $\left.3{ }^{\circ} \mathrm{F}\right)$ follicles is similar between control (iv and v) and PCOS ( $x$ and $x i, x v i$, and xvii) groups. H-E staining showed the morphology of ovaries of control (vi) and PCOS groups (xii). Scale bar in i, ii, iii, iv, and v, vii, viii, ix, x, and xi, xiii, xiv, xv, xvi, xvii, and xviii: $50 \mu \mathrm{m}$. Scale bar in vi and xii: $200 \mu \mathrm{m}$.

(B) Immunofluorescence of CFTR and H-E staining in the ovaries of control (i, ii, iii, iv, v, and vi), testosterone-induced PCOS rat model (vii, viii, ix, $x$, $\mathrm{xi}$, and xii). Reduced CFTR signals are found in cystic follicles in PCOS group (vii and viii) compared with tertiary follicle in the control group ( $\mathrm{i}$ and ii). CFTR signal in the granulosa cells of the secondary and early tertiary follicles is similar between control (iii and iv) and PCOS (ix and $\mathrm{x}$ ) groups. $\mathrm{H}$-E staining showed the morphology of ovaries of control (vi) and PCOS (xii) groups. Scale bar in i, ii, iii, iv, and v, vii, viii, ix, x, and xi: $50 \mu \mathrm{m}$. Scale bar in vi and xii: $200 \mu \mathrm{m}$.

assays revealed that CFTR inhibitor GlyH101, which had been shown to inhibit CFTR with a higher specificity compared with other $\mathrm{Cl}^{-}$channel blockers (Muanprasat et al. 2004), could inhibit primary granulosa cell growth (Fig. 3A). We knocked down CFTR with two siRNAs specifically targeting CFTR. Quantitative RT-PCR showed significant downregulation of Cftr mRNA after transfection of siRNAs (Fig. 3B). Western blot also showed downregulation of CFTR protein by siRNAs
(Fig. 3C). Specificity of the antibody was confirmed by antibody pre-absorption by antigen, which showed disappearance of the CFTR bands (Fig. 3C). Consistent with the result from CFTR inhibitors, when CFTR was knocked down by siRNA, granulosa cell growth was also inhibited compared with the scramble control (Fig. 3C). We also found that in the presence of FSH, GlyH101 also inhibited FSH-stimulated granulosa cell growth (Fig. 3D), indicating possible involvement of CFTR in 

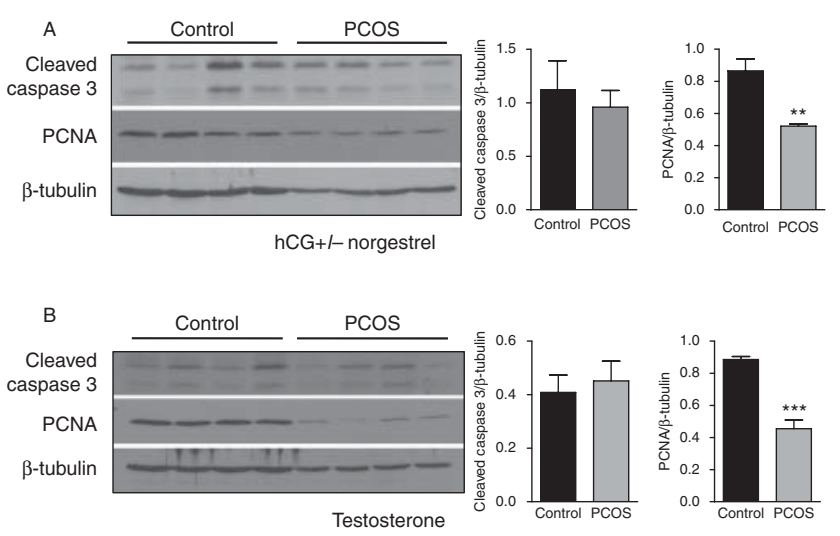

Figure 2 Expression of proteins related to proliferation and apoptosis in ovaries of rat PCOS models. (A) Western blot results of cleaved caspase 3 and PCNA in L-norgestrel + hCG PCOS model ovaries. (B) Western blot results of cleaved caspase 3 and PCNA in testosterone PCOS model ovaries. $n=4$, $t$-test, ${ }^{* *} P<0.01,{ }^{* * *} P<0.001$ compared with control.

modulating the $\mathrm{FSH}$ signaling in regulating granulosa cell proliferation.

\section{CFTR regulates cell cycle and proliferation via the $\mathrm{HCO}_{3}^{-} / \mathrm{sAC} / \mathrm{PKA}$ and ERK pathway}

We further investigated how CFTR regulates granulosa cell proliferation in the primary granulosa cell culture. Knockdown of CFTR by siRNAs led to reduced expression of PCNA in primary granulosa cells (Fig. 4A), consistent with the role of CFTR in promoting granulosa cell proliferation. Similarly, CFTR inhibitor GlyH101 also downregulated PCNA expression in granulosa cells (Fig. 4B). Our previous study had demonstrated that CFTR regulates basal and FSH-stimulated aromatase expression in an $\mathrm{HCO}_{3}^{-} / \mathrm{sAC}$-dependent manner (Chen et al. 2012b). We thus examined the effect of sAC inhibitor $\mathrm{KH} 7$ on PCNA expression and the western blot analysis indicated that $\mathrm{KH} 7(10 \mu \mathrm{M})$ treatment could also downregulate PCNA expression, suggesting the involvement of $\mathrm{SAC}$ in granulosa cell proliferation (Fig. 4B). As sAC is an $\mathrm{HCO}_{3}^{-}$sensor and activator of cAMP/PKA (Chen et al. 2000), we also examined the effect of extracellular $\mathrm{HCO}_{3}^{-}$and $\mathrm{FSH}$ on PCNA expression. Western blot results indicated that neither $\mathrm{HCO}_{3}^{-}$nor $\mathrm{FSH}$ significantly increased PCNA expression; however, $\mathrm{HCO}_{3}^{-}$plus $\mathrm{FSH}$ could significantly upregulate PCNA expression (Fig. 4C). The upregulation of PCNA could be inhibited by GlyH101 and $\mathrm{KH} 7$ (Fig. 4C), indicating the involvement of the CFTR-dependent $\mathrm{HCO}_{3}^{-} / \mathrm{sAC}$ pathway in modulating the FSH-regulated PCNA expression and thus granulosa cell proliferation.

As FSH is known to activate the ERK pathway, one of the important signaling pathways that control granulosa cell proliferation, through a cAMP/PKA-dependent pathway (Cottom et al. 2003, Hunzicker-Dunn \& Maizels 2006), we suspected that the demonstrated involvement of the $\mathrm{CFTR} / \mathrm{HCO}_{3}^{-} / \mathrm{sAC}$ pathway in potentiating the effect of $\mathrm{FSH}$ on PCNA expression might involve activation of ERK. Indeed, our western blot results indicated that $\mathrm{HCO}_{3}^{-}$could slightly enhance ERK phosphorylation, which could be inhibited by GlyH101, KH7, and PKA inhibitor H89 (Fig. 5A). In the absence of $\mathrm{HCO}_{3}^{-}, \mathrm{FSH}$ slightly but not significantly increased ERK phosphorylation. However, $\mathrm{HCO}_{3}^{-}$could enhance the effect of FSH on ERK phosphorylation, which could also be inhibited by GlyH101, KH7, and $\mathrm{H} 89$ (Fig. 5A), consistent with the involvement of the $\mathrm{CFTR} / \mathrm{HCO}_{3}^{-} / \mathrm{sAC}$ pathway.

Cyclin $\mathrm{D}_{2}$ (CCND2) is a cell cycle regulator protein downstream of ERK. It regulates cell cycle progression by promoting $\mathrm{G}_{1} / \mathrm{S}$ transition, and promotes proliferation in granulosa cells. Real-time PCR results indicated that $\mathrm{HCO}_{3}^{-}$could increase Ccnd2 mRNA expression (Fig. 5B). In the absence of $\mathrm{HCO}_{3}^{-}, \mathrm{FSH}$ did not
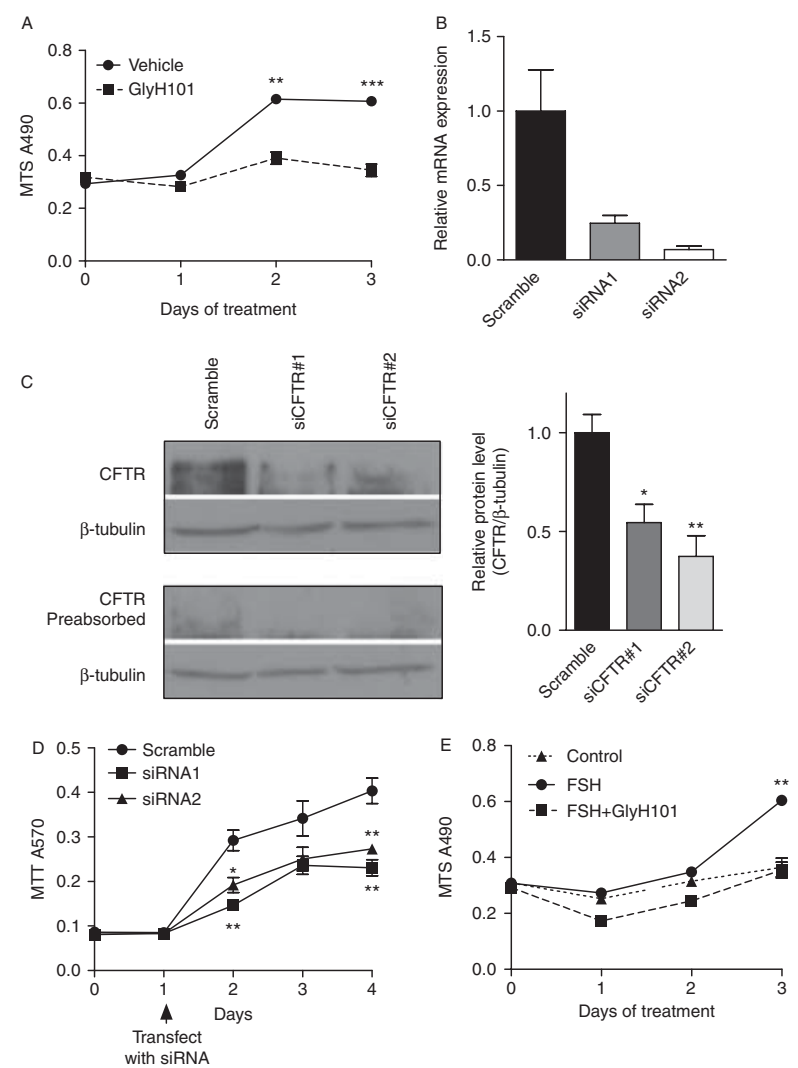

Figure 3 Effect of CFTR inhibition on viability of granulosa cells. (A) MTS assays of granulosa cells treated with $10 \mu \mathrm{M} \mathrm{GlyH} 101$ or vehicle control. (B) Real-time PCR showed that CFTR was knocked down in granulosa cells by two designs of siRNA. (C) Western blot showed that CFTR was knocked down by siRNAs (upper panel). When the CFTR antibody was pre-absorbed by an antigen, the CFTR-specific bands disappeared, confirming the specificity of the antibody (low panel). (D) MTT (3-(4,5-dimethylthiazol-2-yl)-2,5-diphenyltetrazolium bromide) assay of granulosa cell transfected with scramble control or CFTR siRNAs. (E) MTS assays of granulosa cells treated with $10 \mu \mathrm{M}$ GlyH101 or vehicle control in the presence or absence of $50 \mathrm{ng} / \mathrm{ml} \mathrm{FSH} .{ }^{*} P<0.05$; ${ }^{* *} P<0.01$; ${ }^{* * *} P<0.001$ compared with control and $\mathrm{FSH}+\mathrm{GlyH} 101$. 

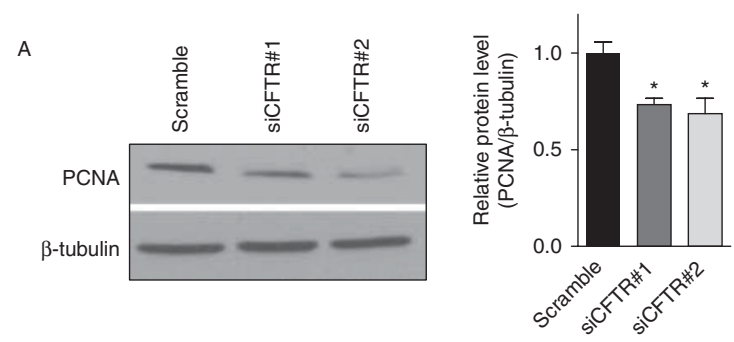

B
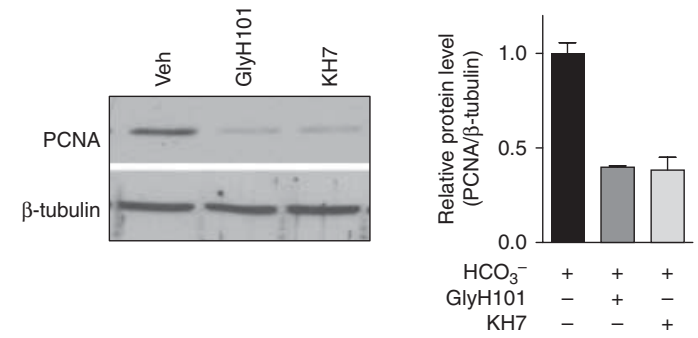

C

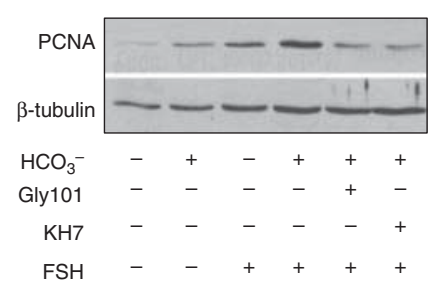

Figure 4 Effect of CFTR knockdown and inhibition on PCNA expression in cultured granulosa cells. (A) Downregulation of PCNA in CFTR knockdown granulosa cells. CFTR was knocked down by two designs of siRNA in granulosa cells at $48 \mathrm{~h}$ after transfection. One-way ANOVA, $* P<0.05$ compared with scramble control. (B) Downregulation of PCNA by CFTR inhibitor GlyH101 $(10 \mu \mathrm{M})$ and sAC inhibitor $\mathrm{KH} 7(10 \mu \mathrm{M})$. (C) PCNA expression is upregulated by FSH in the presence of $\mathrm{HCO}_{3}{ }^{-}$, which is inhibited by $\mathrm{GlyH} 101$ and $\mathrm{KH}$. One-way ANOVA, $* P<0.05,{ }^{* * *} P<0.001$.

significantly increase Ccnd2 expression (Fig. 5B). However, in the presence of $\mathrm{HCO}_{3}^{-}, \mathrm{FSH}$ significantly upregulated $\mathrm{Ccnd} 2$, which was inhibited by $\mathrm{GlyH} 101$, $\mathrm{KH} 7$, and $\mathrm{H} 89$, as well as MEK inhibitor U0126 (Fig. 5B), indicating the role of CFTR in granulosa cell proliferation by regulating the ERK pathway and its downstream target Ccnd2 via the CFTR/ $\mathrm{HCO}_{3}^{-} / \mathrm{sAC}$ pathway. We further examined the level of $\mathrm{p}$-ERK and CCND2 in the rat PCOS model induced by testosterone. Western blot results indicated downregulation of both p-ERK and CCND2 in the ovaries of PCOS group compared with control (Fig. 5C). Together with the observed downregulation of CFTR in PCOS, it supports a role of CFTR in regulating granulosa cell proliferation through ERK and CCND2.

\section{Discussion}

This study on two rat models of PCOS indicates that granulosa cells in the cystic ovaries have decreased cell

proliferation, which may underlie the abnormal follicle development in PCOS. Our finding is supported by another report which used a rat PCOS model induced by disrupting light-darkness cycle and found reduced PCNA in the granulosa cell layers of cystic follicles of PCOS rat compared with normal tertiary follicles in control animals (Salvetti et al. 2009). Decreased granulosa cell proliferation was also reported in bovine PCOS (Isobe \& Yoshimura 2000). However, in studies carried out with PCOS women, either increased proliferation or no difference was found in granulosa cells of early antral follicles (4-8 mm diameter) in PCOS group compared with those in the control group (Takayama et al. 1996, Stubbs et al. 2007, Das et al. 2008). The inconsistent results obtained from the human and rat may be due to the difference in the stage of the follicles examined. The follicles examined in human PCOS studies were at earlier stages, whereas the cyst follicles examined in rat PCOS models were at a later stage, with degenerated granulosa cell layers, which matched the ovarian morphology of PCOS.

Although altered cell proliferation in PCOS granulosa cells has been documented by a number of studies (Takayama et al. 1996, Isobe \& Yoshimura 2000, Stubbs et al. 2007, Das et al. 2008, Salvetti et al. 2009), the underlying mechanism is not well understood. Herein, we have found that CFTR is downregulated in granulosa cells of PCOS rats, accompanied by downregulation of the pro-proliferative gene Pcna. Furthermore, in vitro studies demonstrate that knockdown or inhibition of CFTR led to downregulation of PCNA, as well as decreased cell growth, further supporting the possible involvement of downregulation of CFTR in the abnormal follicle development in PCOS. The involvement of CFTR in regulating granulosa cell proliferation suggests its possible role in normal folliculogenesis during the ovary development in early life and the cyclic wave of follicle growth in reproductive age, defect of which may result in impaired folliculogenesis as observed in PCOS.

As FSH is known to stimulate rapid proliferation of granulosa cells in antral follicles (Robker \& Richards 1998b), the observed altered granulosa cell proliferation in cystic follicles of PCOS suggests a possible defect in $\mathrm{FSH}$-dependent regulation. Our previous study has demonstrated the involvement of the CFTR/ $\mathrm{HCO}_{3}^{-} / \mathrm{sAC}$ pathway in potentiating $\mathrm{FSH}$-stimulated estrogen production, showing reduced CFTR and aromatase expression in PCOS rat models and PCOS patients (Chen et al. 2012b). The present results indicate that this pathway also regulates the basal and FSH-induced ERK activation in granulosa cells, which is a well-known pathway in the regulation of cell cycle and proliferation. Similar to the case of regulation of CREB phosphorylation by CFTR (Chen et al. 2012b), the CFTR/HCO ${ }_{3}^{-}$/ sAC pathway may potentiate the effect of FSH on ERK phosphorylation through the CFTR-dependent $\mathrm{HCO}_{3}^{-}$ entry, activation of SAC, and thus CAMP/PKA cascade. 
In fact, the FSH-induced ERK phosphorylation depends on CAMP and PKA. Unlike CREB, ERK is not directly phosphorylated by PKA, but rather by MEK. PKA is known to phosphorylate and inactivate a $100 \mathrm{kDa}$ tyrosine phosphatase, which in turn inhibits the dephosphorylation pathway of ERK (Cottom et al. 2003). Therefore, the involvement of the $\mathrm{CFTR} / \mathrm{HCO}_{3}^{-} / \mathrm{sAC}$ pathway in modulating ERK phosphorylation may be
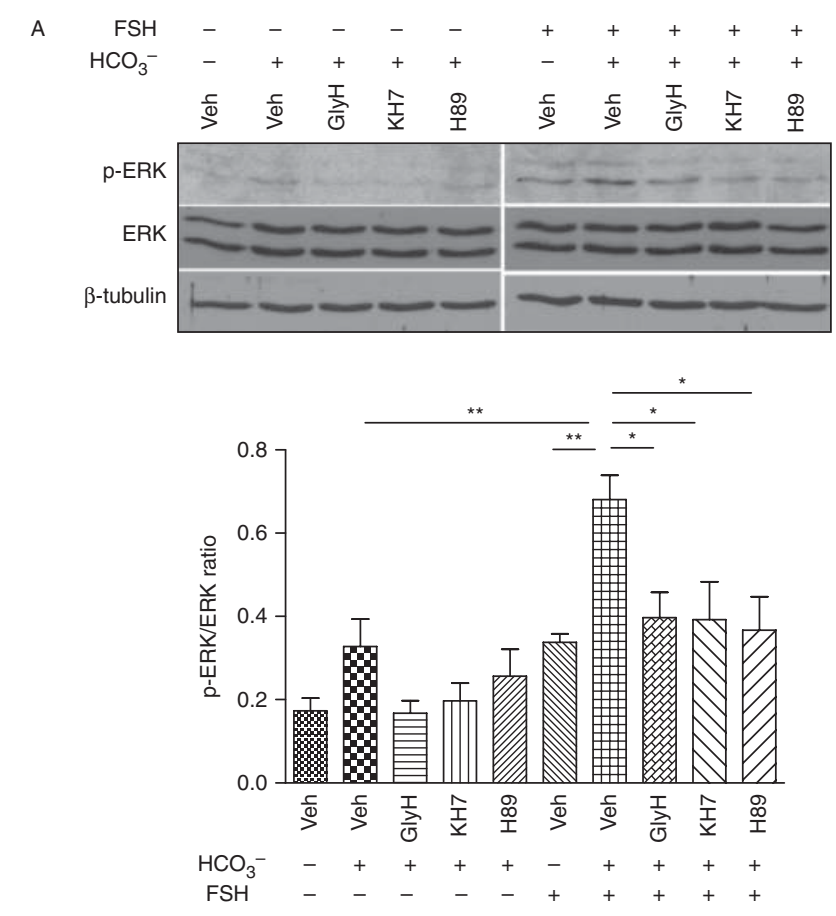

B

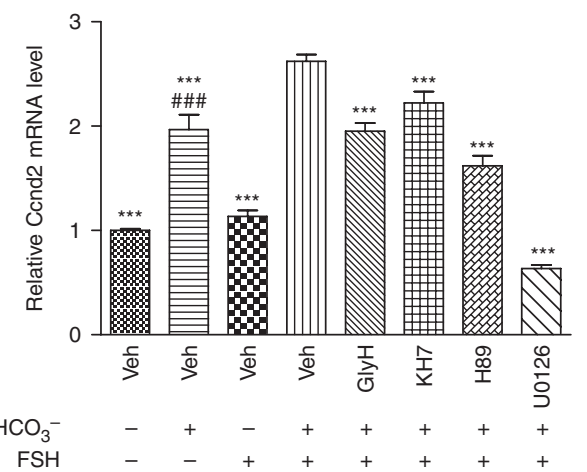

C

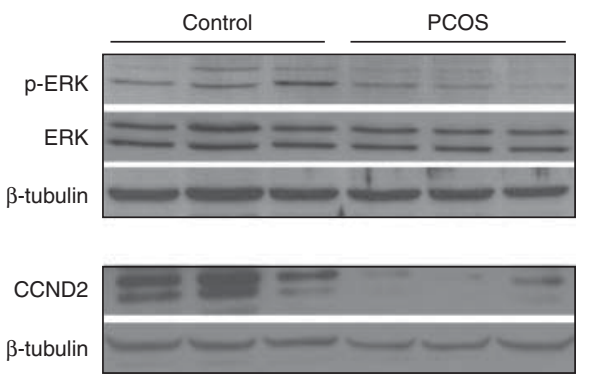

mediated by the PKA-activated inhibition of the tyrosine phosphatase-dependent de-phosphorylation. The ability of the CFTR/ $\mathrm{HCO}_{3}^{-} / \mathrm{sAC}$ pathway to modulate both $\mathrm{FSH}$-stimulated estrogen production, as demonstrated previously, and granulosa cell proliferation, as demonstrated presently, through the CREB and ERK pathways, respectively, suggests that CFTR plays an important role in ovarian functions.

Cleaved caspase 3, which plays a central role in apoptosis, was not significantly changed in PCOS ovaries, as shown by our western blot results (Fig. 2). However, we did not examine its level in follicles of different stages. Therefore, it is unknown whether apoptosis is changed in follicles at certain stages. Studies examining apoptosis in rat PCOS model and PCOS patients by other groups showed increased apoptosis in cystic follicles in rat PCOS model (Salvetti et al. 2009), but reduced apoptosis in early-stage follicles in PCOS patients (Das et al. 2008). Therefore, the alteration in apoptosis status may vary at different stages of follicles in PCOS. It would be of interest to examine whether CFTR may also play a role in granulosa cell apoptosis at different stages of follicle development as CFTR has also been implicated in the regulation of apoptosis (Noe et al. 2009, I'Hoste et al. 2010, Yang et al. 2011).

In conclusion, this study has demonstrated a novel mechanism for regulation of granulosa cell proliferation involving CFTR and its potentiation of FSH effect on the ERK pathway. The present results suggest an important role of CFTR in normal folliculogenesis, mutation or downregulation of which may be responsible for the formation of polycystic follicles observed in both CF and PCOS. Further investigation into how CFTR is downregulated in PCOS and exploration of possible way(s) to re-upregulate CFTR may help develop potential treatment strategy for PCOS.

Figure 5 Enhanced basal and FSH-stimulated ERK phosphorylation and CCnd2 expression by the $\mathrm{CFTR} / \mathrm{HCO}_{3}{ }^{-} / \mathrm{sAC}$ pathway and reduced ERK phosphorylation and CCND2 in PCOS. (A) Western blot results of ERK and phosphorylated ERK in the absence and presence of FSH. $25 \mathrm{mM}$ $\mathrm{HCO}_{3}{ }^{-}$can enhance the effect of FSH on ERK phosphorylation, which can be inhibited by CFTR inhibitor GlyH101 $(10 \mu \mathrm{M})$, sAC inhibitor $\mathrm{KH} 7(10 \mu \mathrm{M})$, and PKA inhibitor H89 $(20 \mu \mathrm{M})$. One-way ANOVA, ${ }^{*} P<0.05,{ }^{*} P<0.01$. (B) Enhanced $C c n d 2$ mRNA expression by the $\mathrm{CFTR} / \mathrm{HCO}_{3}{ }^{-} / \mathrm{sAC}$ pathway. Real-time PCR shows that $25 \mathrm{mM} \mathrm{HCO}_{3}{ }^{-}$ can upregulate $C$ Cnd 2 expression in granulosa cells. ${ }^{\#} P<0.01$ when $\mathrm{HCO}_{3}{ }^{-}+/ \mathrm{FSH}-$ group was compared with $\mathrm{HCO}_{3}{ }^{-}-/ \mathrm{FSH}-$ group. In the absence of $\mathrm{HCO}_{3}{ }^{-}, \mathrm{FSH}$ did not significantly increase $\mathrm{Ccnd} 2$ expression. In the presence of $25 \mathrm{mM} \mathrm{HCO}_{3}{ }^{-}, \mathrm{FSH}$ could upregulate Ccnd2, which can be inhibited by CFTR inhibitor GlyH101 $(10 \mu \mathrm{M})$, sAC inhibitor KH7 $(10 \mu \mathrm{M})$, PKA inhibitor H89 $(20 \mu \mathrm{M})$, and MEK inhibitor U0126 $(10 \mu \mathrm{M})$. One-way ANOVA, ${ }^{* *} P<0.01, * * * P<0.001$ compared with $\mathrm{HCO}_{3}{ }^{-}+/ \mathrm{FSH}+$ group; ${ }^{\# \# \#} P<0.001$ compared with $\mathrm{HCO}_{3}{ }^{-}-/ \mathrm{FSH}-$ group. (C) Western blot showed reduced ERK phosphorylation and CCND2 expression in testosterone-induced PCOS model. 


\section{Declaration of interest}

The authors declare that there is no conflict of interest that could be perceived as prejudicing the impartiality of the research reported.

\section{Funding}

This work is supported in part by the National Natural Science Foundation of China $(81370709,81200422$, the National 973 project of China (2012CB944903) and 81300515), K.S. Lo Foundation, and the Focused Investment Scheme of the Chinese University of Hong Kong.

\section{References}

Aswani N, Taylor CJ, McGaw J, Pickering M \& Rigby AS 2003 Pubertal growth and development in cystic fibrosis: a retrospective review. Acta Paediatrica 92 1029-1032. (doi:10.1111/j.1651-2227.2003.tb02571.x)

Broekmans FJ \& Fauser BC 2006 Diagnostic criteria for polycystic ovarian syndrome. Endocrine 30 3-11. (doi:10.1385/ENDO:30:1:3)

Chan LN, Tsang LL, Rowlands DK, Rochelle LG, Boucher RC, Liu CQ \& Chan HC 2002 Distribution and regulation of ENaC subunit and CFTR mRNA expression in murine female reproductive tract. Journal of Membrane Biology 185 165-176. (doi:10.1007/s00232-001-0117-y)

Chen Y, Cann MJ, Litvin TN, lourgenko V, Sinclair ML, Levin LR \& Buck J 2000 Soluble adenylyl cyclase as an evolutionarily conserved bicarbonate sensor. [see comment]. Science 289 625-628. (doi:10.1126/science. 289.5479.625)

Chen H, Ruan YC, Xu WM, Chen J \& Chan HC 2012a Regulation of male fertility by CFTR and implications in male infertility. Human Reproduction Update 18 703-713. (doi:10.1093/humupd/dms027)

Chen H, Guo JH, Lu YC, Ding GL, Yu MK, Tsang LL, Fok KL, Liu XM, Zhang XH, Chung YW et al. 2012b Impaired CFTR-dependent amplification of FSH-stimulated estrogen production in cystic fibrosis and PCOS. Journal of Clinical Endocrinology and Metabolism 97 923-932. (doi:10.1210/jc.2011-1363)

Cottom J, Salvador LM, Maizels ET, Reierstad S, Park Y, Carr DW, Davare MA, Hell JW, Palmer SS, Dent P et al. 2003 Follicle-stimulating hormone activates extracellular signal-regulated kinase but not extracellular signal-regulated kinase kinase through a 100-kDa phosphotyrosine phosphatase. Journal of Biological Chemistry 278 7167-7179. (doi:10.1074/jbc.M203901200)

Das M, Djahanbakhch O, Hacihanefioglu B, Saridogan E, Ikram M, Ghali L, Raveendran M \& Storey A 2008 Granulosa cell survival and proliferation are altered in polycystic ovary syndrome. Journal of Clinical Endocrinology and Metabolism 93 881-887. (doi:10.1210/jc.2007-1650)

Edson MA, Nagaraja AK \& Matzuk MM 2009 The mammalian ovary from genesis to revelation. Endocrine Reviews 30 624-712. (doi:10.1210/er. 2009-0012)

Han Y, Xia G \& Tsang BK 2013 Regulation of cyclin D2 expression and degradation by follicle-stimulating hormone during rat granulosa cell proliferation in vitro. Biology of Reproduction 88 57. (doi:10.1095/ biolreprod.112.105106)

Hunzicker-Dunn M \& Maizels ET 2006 FSH signaling pathways in immature granulosa cells that regulate target gene expression: branching out from protein kinase A. Cellular Signalling 18 1351-1359. (doi:10. 1016/j.cellsig.2006.02.011)

Hussein MR 2005 Apoptosis in the ovary: molecular mechanisms. Human Reproduction Update 11 162-177. (doi:10.1093/humupd/dmi001)

Isobe N \& Yoshimura Y 2000 Immunocytochemical study of cell proliferation in the cystic ovarian follicles in cows. Theriogenology $\mathbf{5 4}$ 1159-1169. (doi:10.1016/S0093-691X(00)00423-4)

Kayampilly PP \& Menon KM 2004 Inhibition of extracellular signalregulated protein kinase-2 phosphorylation by dihydrotestosterone reduces follicle-stimulating hormone-mediated cyclin D2 messenger ribonucleic acid expression in rat granulosa cells. Endocrinology $\mathbf{1 4 5}$ 1786-1793. (doi:10.1210/en.2003-1029)
Kerem B, Rommens JM, Buchanan JA, Markiewicz D, Cox TK, Chakravarti A, Buchwald M \& Tsui LC 1989 Identification of the cystic fibrosis gene: genetic analysis. Science 245 1073-1080. (doi:10.1126/ science.2570460)

Kumar TR, Wang Y, Lu N \& Matzuk MM 1997 Follicle stimulating hormone is required for ovarian follicle maturation but not male fertility. Nature Genetics 15 201-204. (doi:10.1038/ng0297-201)

I'Hoste S, Chargui A, Belfodil R, Corcelle E, Duranton C, Rubera I, Poujeol C, Mograbi B, Tauc M \& Poujeol P 2010 CFTR mediates apoptotic volume decrease and cell death by controlling glutathione efflux and ROS production in cultured mice proximal tubules. American Journal of Physiology. Renal Physiology 298 F435-F453. (doi:10.1152/ajprenal. 00286.2009)

Muanprasat C, Sonawane ND, Salinas D, Taddei A, Galietta LJ \& Verkman AS 2004 Discovery of glycine hydrazide pore-occluding CFTR inhibitors: mechanism, structure-activity analysis, and in vivo efficacy. Journal of General Physiology 124 125-137. (doi:10.1085/jgp.200409059)

Muniz LC, Yehia G, Memin E, Ratnakar PV \& Molina CA 2006 Transcriptional regulation of cyclin D2 by the PKA pathway and inducible cAMP early repressor in granulosa cells. Biology of Reproduction 75 279-288. (doi:10.1095/biolreprod.105.049486)

Noe J, Petrusca D, Rush N, Deng P, VanDemark M, Berdyshev E, Gu Y, Smith P, Schweitzer K, Pilewsky J et al. 2009 CFTR regulation of intracellular $\mathrm{pH}$ and ceramides is required for lung endothelial cell apoptosis. American Journal of Respiratory Cell and Molecular Biology 41 314-323. (doi:10.1165/rcmb.2008-0264OC)

Norman RJ, Dewailly D, Legro RS \& Hickey TE 2007 Polycystic ovary syndrome. Lancet 370 685-697. (doi:10.1016/S0140-6736(07)61345-2)

Oktem O \& Urman B 2010 Understanding follicle growth in vivo. Human Reproduction 25 2944-2954. (doi:10.1093/humrep/deq275)

Park Y, Maizels ET, Feiger ZJ, Alam H, Peters CA, Woodruff TK, Unterman TG, Lee EJ, Jameson JL \& Hunzicker-Dunn M 2005 Induction of cyclin D2 in rat granulosa cells requires FSH-dependent relief from FOXO1 repression coupled with positive signals from Smad. Journal of Biological Chemistry 280 9135-9148. (doi:10.1074/jbc.M409486200)

Riordan JR, Rommens JM, Kerem B, Alon N, Rozmahel R, Grzelczak Z, Zielenski J, Lok S, Plavsic N, Chou JL et al. 1989 Identification of the cystic fibrosis gene: cloning and characterization of complementary DNA. Science 245 1066-1073. (doi:10.1126/science.2475911)

Robker RL \& Richards JS 1998a Hormone-induced proliferation and differentiation of granulosa cells: a coordinated balance of the cell cycle regulators cyclin D2 and p27Kip1. Molecular Endocrinology 12 924-940. (doi:10.1210/mend.12.7.0138)

Robker RL \& Richards JS 1998b Hormonal control of the cell cycle in ovarian cells: proliferation versus differentiation. Biology of Reproduction 59 476-482. (doi:10.1095/biolreprod59.3.476)

Rommens JM, lannuzzi MC, Kerem B, Drumm ML, Melmer G, Dean M, Rozmahel R, Cole JL, Kennedy D, Hidaka N et al. 1989 Identification of the cystic fibrosis gene: chromosome walking and jumping. Science 245 1059-1065. (doi:10.1126/science.2772657)

Salvetti NR, Panzani CG, Gimeno EJ, Neme LG, Alfaro NS \& Ortega HH 2009 An imbalance between apoptosis and proliferation contributes to follicular persistence in polycystic ovaries in rats. Reproductive Biology and Endocrinology 7 68. (doi:10.1186/1477-7827-7-68)

Shawker TH, Hubbard VS, Reichert CM \& Guerreiro de Matos OM 1983 Cystic ovaries in cystic fibrosis: an ultrasound and autopsy study. Journal of Ultrasound in Medicine 2 439-444.

Stead RJ, Hodson ME, Batten JC, Adams J \& Jacobs HS 1987 Amenorrhoea in cystic fibrosis. Clinical Endocrinology 26 187-195. (doi:10.1111/j. 1365-2265.1987.tb00776.x)

Stubbs SA, Stark J, Dilworth SM, Franks S \& Hardy K 2007 Abnormal preantral folliculogenesis in polycystic ovaries is associated with increased granulosa cell division. Journal of Clinical Endocrinology and Metabolism 92 4418-4426. (doi:10.1210/jc.2007-0729)

Takayama K, Fukaya T, Sasano H, Funayama Y, Suzuki T, Takaya R, Wada Y \& Yajima A 1996 Immunohistochemical study of steroidogenesis and cell proliferation in polycystic ovarian syndrome. Human Reproduction 11 1387-1392. (doi:10.1093/oxfordjournals.humrep. a019405)

Teede HJ \& Norman R 2006 Polycystic ovarian syndrome: insights into the enigma that is PCOS today. Endocrine 30 1-2. (doi:10.1385/ ENDO:30:1:1) 
Trezise AE, Linder CC, Grieger D, Thompson EW, Meunier $\mathbf{H}$, Griswold MD \& Buchwald M 1993 CFTR expression is regulated during both the cycle of the seminiferous epithelium and the oestrous cycle of rodents. Nature Genetics 3 157-164. (doi:10.1038/ ng0293-157)

Wang XF, Zhou CX, Shi QX, Yuan YY, Yu MK, Ajonuma LC, Ho LS, Lo PS, Tsang LL, Liu Y et al. 2003 Involvement of CFTR in uterine bicarbonate secretion and the fertilizing capacity of sperm. Nature Cell Biology 5 902-906. (doi:10.1038/ncb1047)

Xu WM, Shi QX, Chen WY, Zhou CX, Ni Y, Rowlands DK, Liu GY, Zhu H, Ma ZG, Wang XF et al. 2007 Cystic fibrosis transmembrane conductance regulator is vital to sperm fertilizing capacity and male fertility. PNAS 104 9816-9821. (doi:10.1073/pnas.0609253104)
Yang JZ, Jiang X, Dong J, Guo J, Chen H, Tsang LL, Chung YW, Zhang X \& Chan HC 2011 Abnormally enhanced cystic fibrosis transmembrane conductance regulator-mediated apoptosis in endometrial cells contributes to impaired embryo implantation in controlled ovarian hyperstimulation. Fertility and Sterility 95 2100-2106, 2106 e2101-2102. (doi:10.1016/ j.fertnstert.2011.02.036)

Received 23 July 2014

First decision 14 August 2014

Revised manuscript received 26 January 2015

Accepted 2 February 2015 